\title{
ROAD ACCIDENTS AND THE FAMILY DOCTOR \\ Equipment for Use at Roadside Accidents
}

\author{
PETER ASTON,* M.R.C.S., L.R.C.P., D.C.H.
}

British Medical fournal, 1969, 4, 214-217

As road traffic increases and the hospital treatment of casualties becomes more centralized, the role of the general practitioner in the roadside care of accidents will assume greater importance. It is therefore essential that he is equipped with the basic items of equipment to deal with such a situation, even if it is only rarely that he is called to a road accident.

\section{Basic Equipment}

The following list of equipment is basically similar to those being currently prepared by the Royal College of General Practitioners and by the Scottish Home and Health Department :

Wooden tongue depressor

Three packets sterile gauze- 4 in. $\times 4$ in. $(10 \mathrm{~cm} . \times 10 \mathrm{~cm}$.)

Suction apparatus

S.A.L.A.D. ("Save a life a day") or Brook airway

Large blunt-ended scissors

Conforming bandages-four at 6 in. $(15 \mathrm{~cm}$.) wide and four of 3 in. $(7.5 \mathrm{~cm}$.) wide

Four triangular bandages

One packet of Melolin dressings-4 in. $\times 4$ in. $(10 \mathrm{~cm} . \times 10 \mathrm{~cm}$.

Safety pins

Two disposable syringes and needles

Two ampoules of Fortral (pentazocine)

Space rescue blanket or large polyethylene sheet

Intravenous giving-set and Macrodex $500 \mathrm{ml}$. in saline

Biro and notepad

An intravenous giving-set and plasma expander are invaluable for the treatment of hypovolaemic shock, whether of medical, obstetric, or traumatic origin, and should be included even in the most basic kit. Since it is advisable that excited bystanders who are asked to telephone the ambulance service or the hospital are given written information to ensure that a correct message is passed on, a biro and notepad are essential. The National Research Corporation (U.S.A.) rescue sheet, which is made of tough aluminium foil, provides a more effective means of insulating the patient and preventing heat loss than polyethylene. A simple form of suction apparatus may be made from a catheter and reservoir to resemble an adult

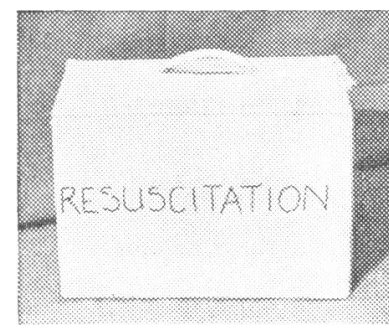

Fig. 1.-Cardboard box containing basic kit FIG. 2.-Fluorescent jacket, Mediflash, plastic waterbottle, Pyc two-way radio, Modulaide kit, case containModulaide kit, case containand torches.

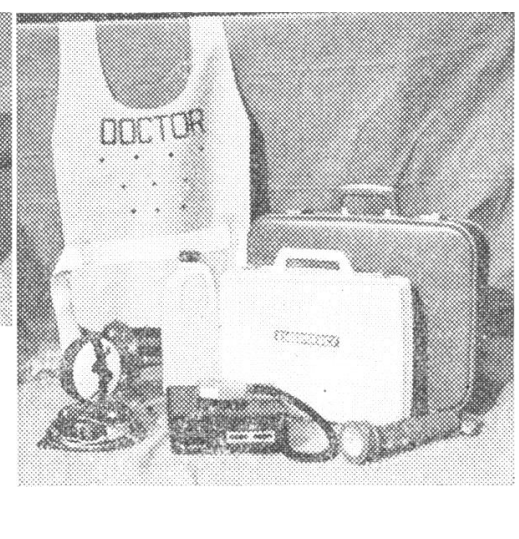

* General practitioner, Bunbury, Cheshire and Clinical Assistant, Accident and Emergency Unit, Crewe Hospital. version of the infant mucus extractor; this will serve to remove blood and saliva, but will not cope with vomiting. The cheaper plastic airways are excellent for maintaining ventilation, but can be a hazard if a patient has a convulsion, since the plastic they are made of is soft enough to be bitten through and possibly inhaled.

All these items of equipment can be stored in a container in the car boot. For the economically minded, the cardboard box which many midwives use for prepacked maternity outfits is a suitable container, as it is cheap, white, and has a small carrying handle. The outside of this should be marked with the expiry date of the plasma expander carried, and the box itself kept inside a polyethylene bag to ensure that the kit remains clean and complete.

\section{Ancillary Aids}

For those general practitioners who are regularly called out by their local police or ambulance service to road traffic accidents, a fuller complement of equipment is needed. If it is assumed that adequate road warning signs and cutting and lifting equipment are provided by the police and fire services, and that the ambulances used for accident work carry oxygen and short spinal splint boards as well as the usual dressings, the following items should find a place in the doctor's car.

For personal protection

Mediflash

"Doctor" sign for the sun visor of car

Orange fluorescent jacket

White overall or coat

Polyethylene or rubber kneeling sheet

Large rubber torch

For vehicle protection

Four-way flashers

Reflective number plates

Fire extinguisher

The use of the Mediflash, combined with dipped headlights, will greatly help the doctor in getting to the scene of the accident as quickly as possible. In this way slow-moving and stationary traffic may be overtaken without generating too much animosity, the police are enabled to identify the car as it arrives at the accident, and ambulance crews can ensure that they are being followed by the doctor at night.

Practitioners working in rural areas and having radiotelephones may find the moderate extra cost of a second channel tuned to the ambulance wavelength useful. When the ambulance control has a direct radio link with the hospital accident unit it will then be easier to ask advice and give details of casualties the unit will be receiving.

To protect the doctor at the scene of the accident from passing traffic, the wearing of arm cuffs or an orange fluorescent jacket is very effective, whereas the small red domed flasher torches and reflecting triangles can easily be knocked over by other motorists. The jacket may be obtained for less than $15 \mathrm{~s}$., 
complete with adjusters, so that it fits whether the person is wearing very light or heavy clothing (those who do not wish to be mistaken for a council roadman can, for 1s. extra, obtain a jacket with "Doctor" stencilled on). ${ }^{1} \quad$ A white boiler suit, of the Royal Air Force pattern, with legs wide enough to put on and take off over shoes, or an old white coat, will save many cleaning bills and also increase personal safety.

\section{Specialist Medical Equipment}

Additional items of medical equipment which should be carried by the general practitioner are listed below:

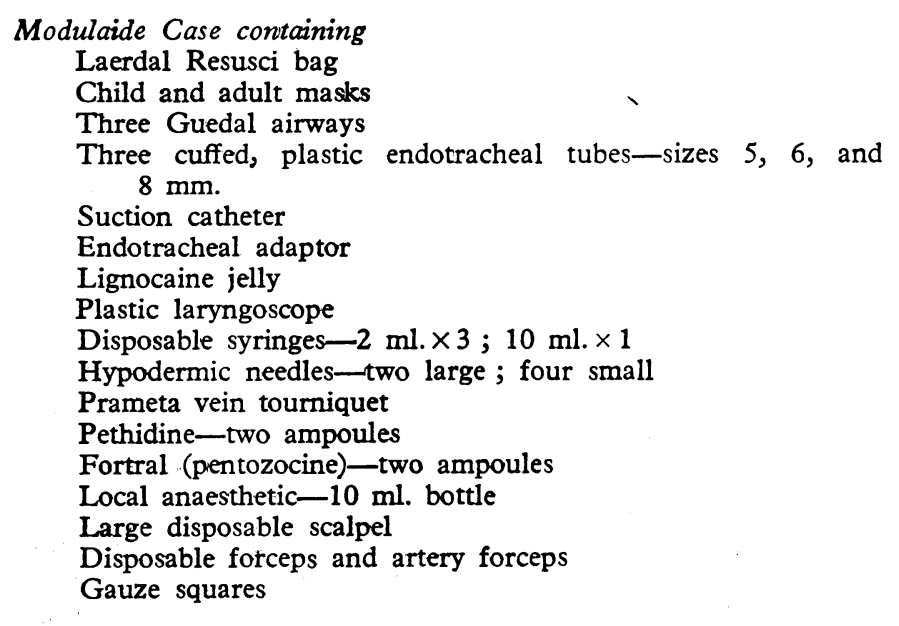

Other case containing

Large blunt-ended scissors

Accident forms and biro

Old stethoscope

Ambu suction pump

Two intravenous giving-sets

Macrodex in saline-500 ml.

Two cannulae (Steriseal or angiocath)

One plain blood bottle

Small instrument roll containing cut-down set and suture material

Sorbo rubber collar

Three inflatable splints

Two large sterile dressings -18 in. $\times 12$ in. $(45 \mathrm{~cm} . \times 30 \mathrm{~cm}$.)

One packet Melolin dressings-4 in. $\times 4$ in. $(10 \mathrm{~cm} . \times 10 \mathrm{~cm}$.

Safety pins

Plastic stomach tube

Sleek waterproof adhesive strapping-1 in. $(2.5 \mathrm{~cm}$.) wide

Plastic bottle of Cetavlon $100 \mathrm{ml}$.

Four to six triangular bandages

Four to six conforming bandages -3 in. $\times 4 ; 6$ in. $\times 6$

Amethocaine eye drops

together with:

One large plastic water-bottle

Since estimating blood pressure, pulse and respiration rates, and pupil reaction and size at the roadside can help a later assessment of the patient, it is useful to carry an aneroid sphygmomanometer, an old stethoscope, and a torch in the emergency kit, and not to have to return to the car for such items.

To record briefly any details of the accident and the patient's condition, a preprinted pad of alternate thin and thick paper sheets, interlined with carbon paper is useful. ${ }^{2}$ In the chaos at many accidents these can act as a reminder of what further information should be obtained-for example, whether or not the patient was unconscious, whether safety belts were worn, base-line blood pressure, pulse and pupil recordings, drugs given, equipment used, and lastly the registration number of the vehicle(s) involved.

\section{ACCIDENT DETAILS}

R.T.A.

Summoned by

Accident at

Patient's Name

Address

Sent to

Accident Cause :

Safety Belts Yes/No

Driver/Passenger

Vehicle

Ins. Co.

B.P.

INJURIES

\section{DRUGS GIVEN}

Apparatus used:

$\mathrm{O}_{2}$ Airway

$$
\begin{gathered}
\text { Jet Splints } \\
\text { Dressings }
\end{gathered}
$$

Sucker

Details of final diagnosis of this patient would be appreciated. Signed Address

\section{Maintaining Respiration}

Air Viva, Sussex, or Ambu bags are all effective for ventilating patients with serious head or chest injuries, but for convenience and durability I prefer the Laerdal Resusci bag. This will not only fold up into a much smaller space than other makes, but it is transparent and has a shelf-life of ten years. The Ambu minipump (Mark 2) is a reliable foot operated sucker, and gives a suction capacity of $300 \mathrm{~mm}$. Hg. Since it is completely mechanical and can be used anywhere, it is preferable to suckers which work off oxygen cylinders or car manifolds. Plastic laryngoscopes, such as the Penlon or Vickers Laerdal, are cheaper and less likely to go wrong than metal ones. The only disadvantage of the Penlon is that the batteries have to be stored separately until required. Portex plastic endotracheal tubes with a spigot attached for the cuff, which eliminates the need for artery forceps, are more convenient and probably less likely to perish than rubber tubes.

The carrying of a muscle relaxant is a matter of anaesthetic skill and personal choice. Personally, I do not carry one, as I regard intubation as a measure reserved for deeply unconscious patients with head or chest injuries. Those drugs which are essential, however, include a local anaesthetic, which can be used when removing a trapped limb from car metalwork, and pethidine or Fortral (pentazocine) for relief of pain, particularly in the case of trapped victims, by slow ir:travenous administration in low doses. Pentazocine is not yet recommended for children or for women in the first trimester of pregnancy, and for this reason pethidine is still an essential item in the kit. In rare cases only, aminophylline, for patients with chest injuries, or Largactil (chlorpromazine) for restless patients with head injuries, may be required, but if these latter are carried in the doctor's ordinary bag it is simpler to limit emergency drugs to pethidine and pentazocine. Morphine should never be used at the roadside, particularly by intramuscular injection. I well remember a lorry driver, trapped by the steering wheel against his chest, who was given morphine $20 \mathrm{mg}$. irt:amuscularly by a passing doctor. He remained in pain during the $n \times x t 30$ minutes while firemen cut him out. Later, in the warmth of the ambulance, absorption of the 
morphine occurred, so that on arrival at the accident unit not only was his respiration depressed, but examination of the chest and abdomen for internal injuries was definitely hindered.

\section{Immobilizing Injured Parts}

Except for elbow injuries inflatable splints provide the easiest way of immobilizing most limb fractures ; an adult arm splint is about the right size for children's leg injuries, and a semiinflated splint makes a passable pillow. Inflatable splints are also excellent for reducing the risk of shock when transporting patients with fractures. Those which can be inflated by mouth, fold up for storage, and have a zip all the way down the front, are preferable. Redisplint (Parke Davis) or Protector (Australian made) are both satisfactory. It is often useful to tind out which sort your local hospital uses and then to buy a different make, as this makes reclaiming much easier. Three sizes of splint should be included in the kit ; a long arm splint, a long leg splint, and a below knee splint. The last is often useful where access to the trapped victim is limited, or the patient is to be taken to hospital in an ordinary small car. (Having spent an embarrassingly long time blowing air into a splint which had already been perforated by headlamp glass, I am now more careful in making sure that the limb and the roadway near it are free from glass and small stones.) In addition, a cervical collar is useful, not only for suspected cervical spine injuries, but for any unconscious patient trapped semi-upright in his vehicle. A collar made from thick sorbo rubber and stockinette is probably as good as the commercially made ones, and wiï not have any metal parts to interfere with $x$-ray examination.

\section{Minimizing Shock and Pain}

The National Research Corporation (U.S.A.) space rescue blanket folded measures 6 in. $\times 2$ in. $(15 \mathrm{~cm} . \times 5 \mathrm{~cm}$.) but will open out to 56 in. $\times 84$ in. $(140 \mathrm{~cm} . \times 210 \mathrm{~cm}$.). It is excellent for covering and insulating patients-since cutting a lorry to release a trapped driver is of ten a lengthy process, even when he is only trapped by the legs. Giving a small dose of intravenous pethidine (10 mg. to $20 \mathrm{mg}$. intravenously) or pentazocine, and wrapping the patient in the rescue sheet, which gets less in the firemen's way than a blanket, both help to reduce shock and pain. A Prameta vein tourniquet is suitable for children and adults of any size. It is useful when giving intravenous analgesia and when setting up an intravenous infusion, which may be required when there is some delay in the patient

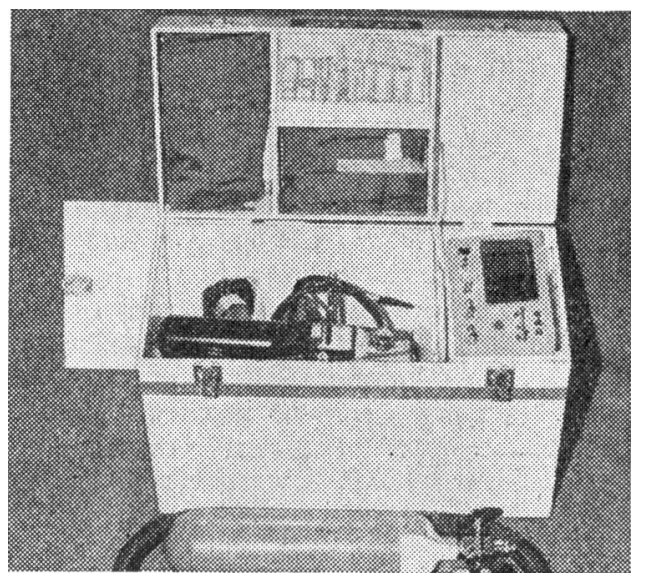

FIG. 3.-Wooden box containing comprehensive equipment from accident unit, including - in addition to items carried by general practitionerEntonox apparatus, tape recorder, cardiograph, and oxygen. reaching hospital. If the intravenous cannula used is placed in a mid-forearm vein, any splintage required can be provided by the empty giving-set box. Macrodex in saline is easier to carry than plasma, since it does not affect later crossmatching, and is also more suitable than rheomacrodex, since it is less affected by changes in temperature. Furthermore, Macrodex is cheaper and more useful for domiciliary obstetrics, one sphere where resuscitation before transportation is already accepted.

Dr. Roger Snook, the inventor of the Mediflash, has recently tried out an inhalant analgesic apparatus which gives a nitrous oxide and oxygen mixture (Entonox). The hypotensive effect of this mixture is minimal compared with an intravenous analgesic, and, since the apparatus raises the oxygen content of the air breathed to $50 \%$, it is of definite use in combating pain and shock. In view of its cost and weight, which is $13 \frac{1}{2} \mathrm{lb}$. ( $6 \mathrm{~kg}$.$) , it could well be included with the spinal board { }^{3}$ and vacuum mattress ${ }^{4}$ as a useful item of equipment to be carried in the accident ambulance.

\section{Dressing Wounds}

The largest commercially available dressings I have been able to locate are Johnsons' sterile Surgipads, which measure 18 in. $\times 9$ in. $(45 \mathrm{~cm} . \times 28 \mathrm{~cm}$.). These can still be too small, however, for some major injuries, and a supply of the North Riding Road Accident After Care Scheme's 18 in. $\times 12$ in. $(45 \mathrm{~cm} . \times 30 \mathrm{~cm}$.) and 14 in. $\times 12$ in. $(35 \mathrm{~cm} . \times 30 \mathrm{~cm}$.) crash dressings should therefore be carried. For smaller wounds Melolin non-stick dressings held in place by conforming bandages (Kling or Crinx) are quite satisfactory. These are easier to apply than conventional bandages and nurses in accident units are quite prepared to cut these off, whereas they invariably remove crêpe bandages by unwinding, often to the patient's discomfort.

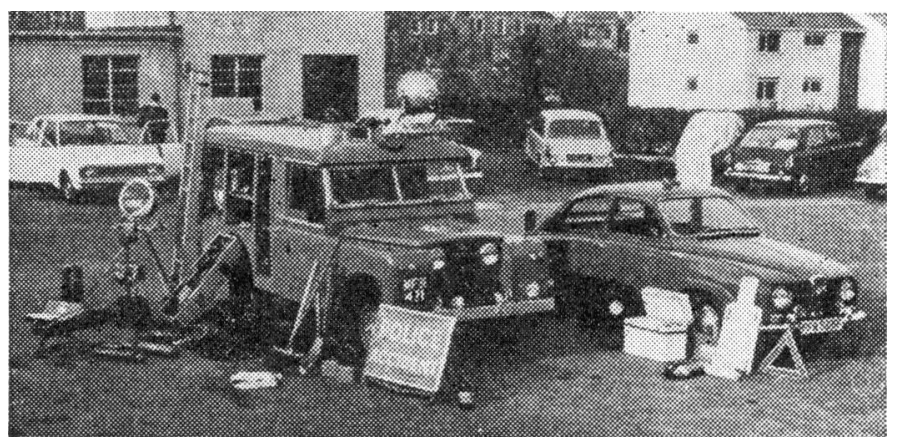

FIG. 4.-Fire tender with cutting gear, doctor's car with Mediflash, and spinal board.

\section{Care of the Equipment}

The fibreglass case of the Modulaide equipment is ideal, but for the rest of the equipment there is no other suitable container which is available commercially. Senior-partners midwifery bags are the only doctors' cases large enough to carry the remainder of the equipment. But these are too heavy, and, like the canvas Ambu holdall, are dark in colour and therefore poorly visible at the roadside. Having once had difficultyafter crawling into an overturned car in a field-in locating my effectively camouflaged brown case less than four feet away, I now prefer a light-coloured one. A box made of lightweight wood, painted white and with a leather rather than metal carrying handle, is a suitable alternative until some manufacturer produces a large white fibreglass case. Wrapping most items in polyethylene bags helps when checking the contents for what has been used and needs replacing, and also keeps them clean.

Care of road traffic accidents has until recently been completely orientated towards the hospitals. For the seriously injured specialist care at all stages would be ideal, but at the 
scene of the accident-particularly in rural areas-general practitioners are, as in many other emergencies, the first available doctors. Therefore with suitable equipment and training, particularly from anaesthetic colleagues, they can-when working in co-operation with the modern, well-trained ambulancemanmake useful observations and initiate treatment at the roadside which will help to reduce the suffering and mortality of a major twentieth-century disease.
I am indebted to Mr. T. McSweeney, F.R.C.S., consultant orthopaedic surgeon, South Cheshire hospitals, and Dr. K. C. Easton, Catterick, Yorkshire, for their helpful advice when preparing this article.

1 G. Pike and Sons, Manchester.

2 Rubell Print, Bunbury, Nr. Tarporley, Cheshire.

${ }^{3}$ Original spinal board was made by Dr. J. E. Farrington.

${ }^{3}$ Uriginal spinal board was made by Dr. J. E. Farrington.

\section{ANY QUESTIONS ?}

We publish below a selection of questions and answers of general interest.

\section{Disinfecting Hydrotherapy Bath}

Q.-What should be added to the water (and in what concentration) to prevent crossinfection between patients in a hydrotherapy bath containing several hundred gallons of water at, or slightly above, body temperature used for the treatment of a number of people in succession?

A.-Bacteria and viruses rapidly accumulate in bath water unless adequate concentrations of disinfectant are present. ${ }^{2}$ The only satisfactory way of preventing this in a large hydrotherapy bath is to treat it by the methods described for swimming-poolsthat is to say, continuous filtration and chlorination. $^{3}$

A concentration of free chlorine between 0.2 and 0.5 p.p.m. is required, and the methods for maintaining this are described in The Purification of the Water of Swimming Baths."

\section{REFERENCES}

I McLean, D. M., Pediatrics, 1963, 31, 811. Hygiene, 1966, 64, 489 .

s Bolton, E., Physiotherapy, 1968, 54, 232.

The Purification of the Water of Swimming Baths, 1964. London, H.M.S.O.

\section{Malarial Prophylactics and the Liver}

Q.-Is there a particular choice of malarial prophylactics in patients who have a history of infectious hepatitis but whose liver function tests are normal?

A.-The hepatotoxic qualities of the standard malaria prophylactics are of such a low order that they may be ignored, even in patients suffering from infectious hepatitis. The selection of a prophylactic need not therefore be influenced by a history of hepatitis.

\section{Pharyngolaryngectomy}

Q.-Do the thyroid and parathyroid glands have to be removed in a pharyngolaryngectomy, and is replacement therapy needed afterwards?

A.-It is usually necessary to remove all the thyroid gland during a pharyngolaryngectomy. Parathyroid tissue may be found anywhere between the hyoid bone and the pericardium, but $95 \%$ of it is close to the thyroid gland. Histological studies have shown that most of this parathyroid tissue is removed during pharyngolaryngectomy, especially when dissection of the superior mediastinum is undertaken at the same time. If the neck has been irradiated before operation the remainder of the parathyroid tissue will probably be damaged by injury to the end arteries supplying it. ${ }^{1}$

After operation the patient needs longterm thyroid replacement therapy. A dose of thyroxine of $0.1 \mathrm{mg}$. twice daily is usually sufficient. Frequent serum cholesterol levels should be measured to recognize myxoedema. Parathyroid replacement therapy with calcium tablets $6 \mathrm{~g}$. a day and calciferol 50,000 units daily (with frequent monitoring of the serum calcium level) is usually adequate. Dihydrotachysterol is occasionally used. ${ }^{2}$

\section{REFERENCES}

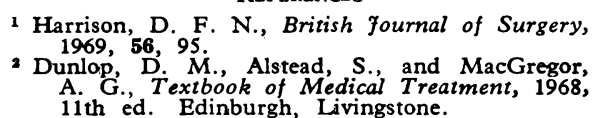
A. G., Textbook of Medical Treatm

\section{Bleeding after Abortion}

Q.-What measures should be taken to stop continuing bleeding after a dilatation and curettage for abortion?

A.-Continued bleeding after vaginal evacuation of the products of conception suggests one of the following diagnoses: (1) an atonic uterus; (2) placental tissue remaining in the uterus ; (3) uterine infection; (4) trauma; (5) a coagulation defect; or, rarely, (6) chorionepithelioma.

The first step is to make sure that the uterus is contracted. Ergometrine $0.5 \mathrm{mg}$. should be given intravenously while the uterus is gently compressed to evacuate blood clot and then massaged until it hardens. If the uterus persistently relaxes the bladder should be emptied through a catheter and a continuous intravenous infusion of oxytocin ( 5 units per litre) should be set up. When uterine atony is the cause of persistent bleeding these measures should suffice to control it.

When there is doubt about the completeness of the abortion the uterine cavity should be gently re-explored, preferably with a finger. The placental site may sometimes feel very shaggy, which sometimes gives rise to the suspicion that placental tissue still adheres to the uterine wall. Further curettage urider these circumstances will lead only to fresh bleeding and the removal of myometrium, which is to be avoided.

If the circumstances suggest that there may be a uterine infection bleeding should be controlled by the oxytocic measures outlined above and appropriate antibiotic treatment should be given.

The commonest injury that causes continuing bleeding after curettage is a tear at the level of the internal cervical os. Previous events, careful exploration of the uterine cavity, and the clinical state of the patien will exclude an intraperitoneal injury and haemorrhage. Simple perforations of the uterine fundus seldom cause continued bleeding. Bleeding from tears of the cervix can usually be controlled by manual compression of the uterus combined with the administration of oxytocic drugs. Occasionally brisk bleeding from vulsellum punctures of the anterior lip of the cervix needs to be controlled with a mattress suture of catgut.

Coagulation defects should be suspected when there is a history of a tendency to bleed or the curettage is for a missed abortion. In these cases the blood issuing from the vagina fails to clot, and further investigations will be required to establish the precise nature of the defect in the clotting mechanism for accurate treatment. While these investigations are being carried out quadruple strength plasma provides a source of fibrinogen.

Chorionepithelioma should be suspected when fleshy haemorrhagic material continues to be removed from the placental site and is associated with persistent fresh blood loss.

With modern oxytocic therapy hot douches and packing of the uterus are seldom required.

\section{Notes and Comments}

Topical Insulin.-Dr. R. CARRUTHERs (Launceston, Tasmania) writes: With reference to the answer to this question ("Any Questions ?" 20 September, p. 703), your expert states that he was unable to find any reference to this. I used topical insulin after reading the article by Paul, ${ }^{1}$ and was impressed when I saw accelerated healing in an ulcer while an apparently similar ulcer on the other leg did not heal until also treated with topical insulin.

Balassa $a^{2}$ and, more recently, Lopez and Menas have also described their observations of the use of topical insulin in diabetics, the former quoting work published in 1930 .

\section{REFERENCES}

Paul, T. N., Lancet, 1966, 2, 574 Balassa, J., Medical fournal of Australia, 1967 2, 604.
Lopez, J. E., and Mena, B., Lancet, 1968, 1, 